\title{
Impact of Using Social Marketing Principles on Promoting Breastfeeding Practices and Physical Growth: an Egyptian Community Based Longitudinal Study
}

Ammal M. Metwally ( $\square$ ammal_mok@yahoo.com ) National Research Centre (Affiliation ID: 60014618)

Walaa A. Basha

National Research Centre (Affiliation ID: 60014618)

Ghada A. Abdel-Latif

National Research Centre (Affiliation ID: 60014618)

Sara F. Sallam

National Research Centre (Affiliation ID: 60014618)

Inas R. El-Alameey

National Research Centre (Affiliation ID: 60014618)

Manal H. Abuelela

Research Institute of Ophthalmology

Hala A. Amer

National Research Centre (Affiliation ID: 60014618)

Walaa Yousef

National Research Centre (Affiliation ID: 60014618)

Amira A. Goda

National Research Centre (Affiliation ID: 60014618)

Galal A Elashry

National Research Centre (Affiliation ID: 60014618)

Doaa E Ahmed

National Research Centre (Affiliation ID: 60014618)

Nihad A. Ibrahim

National Research Centre (Affiliation ID: 60014618)

Sahar A. El-Masry

National Research Centre (Affiliation ID: 60014618)

Nayera E Hassan

National Research Centre (Affiliation ID: 60014618)

Soha M. Abd El Dayem

National Research Centre

Wafaa A. Kandeel 
Theodor Bilharz Research Institute

\section{Ebtissam M. Salah}

National Research Centre (Affiliation ID: 60014618)

\section{Rokia .Abd Elshafy S. El Banna}

National Research Centre (Affiliation ID: 60014618)

Iman H Kamel

National Research Centre (Affiliation ID: 60014618)

\section{Enas M. Abdelhamid}

National Research Centre

Mohamed A Mohamed

Cleveland Clinic Children's

Walaa S. Mahmoud

National Research Centre (Affiliation ID: 60014618)

\section{Research Article}

Keywords: nutritional interventions, social marketing principles, breast feeding practices, physical growth

Posted Date: September 9th, 2021

DOl: https://doi.org/10.21203/rs.3.rs-507284/v1

License: (c) (i) This work is licensed under a Creative Commons Attribution 4.0 International License. Read Full License 


\section{Abstract}

Background: Improving breastfeeding practices does not always link to interventions relying only on improving nutritional awareness and education but needs cultural and behavioral insights.

Aim: Our study provided educational intervention through the use of the social marketing (SM) approach which was respectable to societal norms allowing more conscious choices by mothers to achieve the maximum potential of physical growth of their infants. This study evaluated the effectiveness of the used approach for improving breastfeeding practices and the physical growth of infants aged up to 2 years.

Methods: A quasi-experimental intervention design with posttest-only control design was done along 3 years duration with 24 months of intervention and follow up for motivating mothers' voluntary behavioral change towards breastfeeding promotion using SM principles: product, price, place, and promotion. The interventions targeted 646 pregnant women in their last trimester and mothers of children up to 2 years in addition to 1454 women in their childbearing period.

Results: Most of the mothers showed increased awareness about the benefits of breastfeeding and became interested in breastfeeding their children outside the house using the breastfeeding cover (Gawn). Early breastfeeding initiation, exclusive breastfeeding (EBF) under 6 months, frequency of breastfeeding per day, percentage of infants who continued breastfeeding till 2 years, were significantly increased from $30 \%, 23 \%$, $56 \%$, and $32 \%$ to $62 \%, 47.3 \%, 69 \%$, and $43.5 \%$ respectively. With the attention of the nutritional educational sessions three or more times, the majority of indicators had the most significant improvement. The girls who recorded underweight results compared to boys, were significantly improved after the intervention (from $66.7 \%$ to $18.8 \%$ ). At the same time, girls that were found to be obese before the intervention (15.4\%) became no longer obese.

Conclusions: Nutritional interventions that are based on the use SM approach showed improvement for the majority of the key performance indicators. Although they were doubled their value before the intervention yet the majority were still modest (below $50 \%$ ). With sustained use of the SM approach, infants will achieve their maximum potential for physical growth through providing economically disadvantaged mothers with breastfeeding support.

\section{Background}

Breastfeeding is one of the foundations of child development, health, and survival. The World Health Organization (WHO) recommends that breastfeeding has to be initiated within the first hour after birth, infants have to be exclusively breastfed for the first 6 months; complementary foods have then be introduced, with continued breastfeeding until 2 years of age or older (1).

Early and exclusive breastfeeding has been found to reduce all-cause and infection-related mortality by $45 \%$; such as diarrhea and respiratory infection also there is some evidence that it is linked to a reduction in the risk of obesity and diabetes later in life $(2,3)$. Moreover, breastfeeding can prevent 823.000 child deaths every year, making it arguably the most effective child mortality prevention intervention (4). 
Breastfeeding is directly linked to two of the United Nations Sustainable Development Goals (SDGs), SDG 2 and SDG 3, which focus on improved nutrition and maternal and child health, respectively and indirectly improving breastfeeding practices will progress towards SDGs 4, 5, and 6 (breastfeeding impacts on intelligence, enhancing economic and human capital development), as well as SDG 10 by reducing inequality between the rich and poor $(2,4)$. Thus, there is a badly need to improve breastfeeding practice i.e. increase the duration of exclusive breastfeeding to ensure universal coverage of this practice. Therefore, there is a consensus agreement that exclusive breastfeeding is a priority area, with $50 \%$ global targets by 2025 increased to be at least $70 \%$ of children being exclusively breastfed till 6 months by 2030 (5).

Considering all of the suggestions and the well-documented health interests of breastfeeding, cognitive and socioemotional development $(6,7,8)$, In the Middle East, the number of mothers who particularly breastfeed for six months is recorded to be $20.5 \%(9,10)$. Meanwhile, the Egypt Demographic and Health Survey (EDHS) showed that the rate of exclusive breastfeeding dropped from $70 \%$ on 2008 (11) to a little more than $50 \%$ on 2014 (12) for infants under three months of age. Again the $30 \%$ of infants who were $4-5$ months of age during 2008 dropped to $13 \%$ during 2014. At first glance, this indicates deterioration in such practice. Even more, Egypt appears to be doing the same or even worse than the rate of EBF amongst developing countries, demonstrating that Egypt is far from optimum. In Egypt, the understanding of why many mothers experienced difficulties in maintaining exclusive breastfeeding till six months of life is still a gap (13)

Whereas, barriers continue to dominate women's good practices for breastfeeding, addressing any encountered barriers, required besides the educational and promotional programs, supportive positive environment to make healthy options available. To achieve successful breastfeeding overcoming difficulties for optimal feeding practices, the World Health Organization (WHO) recommended breastfeeding counseling (14-17). Provision of breastfeeding counseling could be achieved through different approaches, of which is social marketing (SM). SM defines as the usage of marketing to design and apply programs to promote socially beneficial behavior change (18). The ability to achieve consistent changes in population behaviors could be considered the most reliable assessment tool for the effectiveness of SM on public health promotion (19).

The current study focused on improving breastfeeding practices by counseling mothers through the use of social marketing principles. We aimed to appraise the efficiency of the interventions executed to encourage breastfeeding among economically disadvantaged families on early breastfeeding initiation rates (within one hour of birth), duration rates till 2 years, rate of exclusive breastfeeding for 6 months with no water or herbal fluids during the first 6 months.

\section{Methods}

\subsection{Study Design}

The study was an interventional evaluation study with before and after comparison conducted over three years duration starting from Jan. 2017 till Jan. 2020. A quasi-experimental design with random selection and posttest-only control design was done. Two villages were included in the study as intervention and control villages. Two methodological approaches were used; the first was through comparing the conducted practices 
as a result of the intervention between the intervention villages with those who did not receive any intervention in the non-intervention village. The second was through looking for the direct evidence: Assessing the change of the breastfeeding practices as well as the growth before and after the interventions within the intervention village which mean that the study group served as self-control.

\subsection{Study setting and participants:}

The intervention village: El Othmanyia village of El Mahala El Kobra district- Gharbyia governorate was selected as the site of the project implementation. El Othmanyia village total women in the childbearing period (19-45 years) were 2100 . The control village was chosen as a matched group from a nearby adjacent control village (Nemra el Basal village) with similar socioeconomic status.

The selected villages have powerful and active well organized community-based associations with on-ground community health workers (CHWs) who were trained and serve as key players for the provision of the motivational messages to the target groups.

\subsection{Target groups:}

\subsubsection{Primary group (direct and indirect beneficiaries)}

The direct beneficiaries included pregnant women in their third trimester to help them have the best start and initiate their breastfeeding as soon as possible after birth, also mothers of newly born (0-6 months) and mothers of infants aged 6 months to 2 years old. A total of 600 mothers of infants aged less than 2 years and 46 pregnant women were engaged in the interventional study as a direct beneficiaries.

Women in their childbearing period were also targeted as indirect beneficiaries $(n=1454)$. A total number of 2100 women, including women who intended to breastfeed their infants and those who did not and who signed informed consent forms, were targeted. The age range of the women enrolled in the study was 19-45 years.

\subsubsection{The secondary target group}

People who influence mothers to breastfeed and those having a strong influence over women's decisions about feeding their infants. This group included the CHWs, who are healthcare providers (nurses and physicians).

\subsection{Phases of the study:}

The study was conducted in phases; the first was the formative assessment research followed by the interventions phase and ended by evaluation for measuring the outcome and impact.

\subsubsection{Basis for sample size calculation during the assessment and evaluation phases $(20,21)$ :}

A sample size of 141 houses produced a two-sided $90 \%$ confidence interval with a width equal to 0.100 when the sample proportion for exclusive breastfeeding up to 6 months of age is 0.130 (12) which was rounded to 150 households. Houses were randomly selected out of houses of the direct beneficiaries; those who have pregnant women in their last trimester and/or mothers of infants $0-2$ years were enrolled in the study. A total 
number of 200 women who were resident in these houses and who fulfilled the selection criteria were included in the assessment and evaluation stages through a longitudinal study together with their infants up to 2 years.

\subsubsection{Phase one; assessment phase:}

Participant in-depth interviews and formative research were used to collect data from the beneficiaries. The indepth interview focused on listening from the attending mothers about problems they met in their previous breastfeeding experience and offering the best solution for each. Community consultation to help identify the "Best practices", those appropriate, convenient, and suitable with local culture, capabilities, and the physical environment was also conducted. Meanwhile, the formative research was used to assess the current situation of breastfeeding practices and identify the behaviors to be targeted, pricing, and the promotional messages. The formative research also identified the factors that influenced mothers' decisions to breastfeed and those that hinder or encouraging women to breastfeed as well as the spokespersons for promoting breastfeeding. All practices were determined according to the designed pre-tested questionnaire.

\subsubsection{Phase two; intervention phase:}

The interventions included capacity building of the activities' implementers (the secondary target group) by the research team specialists from the National Research Center of Egypt which lasts for 4 months. The training was directed to $7 \mathrm{CHWs} 5$ nurses and 2 physicians of the rural health unit of the intervention village. So that they became community educators delivering the right messages about proper breastfeeding practices to caregivers. They were targeted by the educational toolkit developed by the related researchers which tailored more specifically to their needs and respected their norms according to the finding of the assessment phase.

Health education and counseling interventions targeted 646 of the direct beneficiaries and 1454 women in their childbearing period (indirect beneficiaries) with a total no of 2100 women. The longitudinal interventions followed over 646 mothers from early pregnancy throughout their infant's second year of life.

Counseling sessions related to the importance, early initiation, continuation of mothers to successfully breastfeed their infants and identifying the warning signs that need breastfeeding consultant intervention were delivered along 12 months to target the primary beneficiaries. For Each mother 10 messages were delivered along 3 months; 3 messages were covered in the first session during the first month and 4 messages were added and covered in the second session during the second month and 3 different messages were added during the third session during the third month. Then, this is followed by repeating the same messages every 3 months. Accordingly, along 12 months implementation 4 rounds were conducted to cover delivering the messages to all targeted participants. The first set of messages were attended by 646 pregnant women and lactating mothers for children less than 2 years in addition to 1454 women in the childbearing period. The second set of messages was attended by 406 mothers, 1392 women respectively, and the third by 313 mothers and 1306 women respectively. The activation process for the targeted primary and secondary groups with follow up was conducted along 28 months.

Flow diagram of the educational interventions implementation process, messages, reach, engagement, tools, giveaways and demonstrations used to disseminate motives to cause change, was illustrated in Fig. 1 
The interventions were based on the use of social marketing approach. This approach was based on using the motives for successful breastfeeding practices and overcoming the detected obstacles and factors contributing to declining of breastfeeding practices for improving breastfeeding practices along one years of interventions for educating the targeted primary group.

\subsubsection{Phase three; evaluation phase:}

The end-of-study evaluation was done once the interventions had been completed through using a participatory approach by $\mathrm{CHWs}$ under the supervision of the study team. To measure the intervention effectiveness, mothers and their infants were assessed and evaluated by the same structured questionnaires to test the breastfeeding practices and infants' growth before and after the interventions. Moreover, to measure if mothers liked the activation process or not both the reach (first-time attendance) and the engagement (more times of attendance). Measuring the reach and engagement was done for the direct primary group (the direct beneficiaries)

The key performance indicators (KPIs) to monitor the success of the interventions were:

Core indicators:

1. Early initiation of breastfeeding

2. Exclusive breastfeeding (EBF) under 6 months

3. Continued breastfeeding at 1 year

4. Continued breastfeeding at 2 years

5. Children ever breastfed

6. Predominant breastfeeding under 6 months

7. Bottle feeding

8. \% Responsiveness to cues of hunger and satiety

The agreed definitions of the relevant Breastfeeding: the child has received breast milk (direct from the breast or expressed). Exclusive breastfeeding: The infant has received only breast milk from his/her mother or a wet nurse, or expressed breast milk, and no other liquids or solids with the exception of drops or syrups consisting of vitamins, mineral supplements, or medicines (22) Predominant breastfeeding "allows" Oral Rehydration Salts (ORS), vitamin and/or mineral supplements, ritual fluids, water and water-based drinks, and fruit juice. Other liquids, including non-human milk and food-based fluids, are not allowed, and no semi-solid or solid foods are allowed.

2.5 Social marketing (SM) approach:

Health education through using social marketing principles (18): The implementation of the market plan focused on increasing the reach and engagement of mothers to have a profound impact and sustained success of breastfeeding. The marketing plan included the following:

2.5.1 Target Behaviors (outcome)

1. Increase breastfeeding early initiation rates

2. Increase breastfeeding duration rates till 2 years

3. Increase rate of EBF under 6 months 
4. Increase general public support for breastfeeding practices

\subsubsection{Product(s)}

The Product is breastfeeding. The choice of breastfeeding benefits that has been emphasized was identified during formative research according to each targeted behavior.

The formative research indicated that the emotional benefits to the baby were emphasized more than the health benefits be more influential with mothers.

\subsubsection{Price}

For addressing the price factor, the marketing plan focused on interventions to lower the identified costs (barriers to breastfeeding and Faulty beliefs) or make them more acceptable.

Encouragement of responsive feeding of mothers' to their babies' cues of hunger and satiety is free of charge. The following guiding principles during breastfeeding were provided and all are free of charge; feed directly or assisted, feed slowly and patiently, encourage feeding without forcing, avoid distractions while talking and looking at the child.

Moreover, behavioral change through the SM approach was applied to overcome the identified barriers through teaching the health providers to increase the awareness and concern of the mothers of breastfeeding's motives (benefits) and help mothers develop ways to lower the costs (barriers) most relevant to them personally.

\subsubsection{Place}

The Place factor was addressed through using the governmental public health facilities (the village rural health unit) and the village community-based associations to make these public settings more welcoming to breastfeeding women. Moreover, nursing women were also reached at their homes through the CHWs.

Interventions to facilitate support for breastfeeding practices through professional training directed towards nurses, physicians, and health workers at the rural health unit as well as the village community-based association's members so that they could discuss breastfeeding with family members and friends

\subsubsection{Promotion and Motives:}

The promotional messages targeted factors detected to motivate and deter from encouraging women to breastfeed. The promotion messages used were out of the reported motives by ever breastfed mothers (190 mothers) that were expressed by more than half of the mothers; mainly: Save money, time, and effort, increase the mother-baby bond, and boost the child's immunity. In addition reasons for not using the pacifier were also added to the motives.

\subsubsection{Slogan:}

The slogan of promotion to breastfeeding "nurse me like a baby" was used for message distribution. Catchy, innovative messages were developed on the basis of the detected motives and that was in line with the village 
local context and according to their cultural and behavioral insights. The messages were converted to posters and cards.

The messages were from babies to their mothers "one thing I wanted to tell you, my mom, once I'm out nursing me like a baby. Breastfeed me for the 1 st 6 months, and don't give anything else before I'm 6 months, continue breastfeeding me for up to two years. The only food I will love is the one coming from you. When you breastfed me you will not only save money, time and effort but also increase my immunity and I feel you and you feel me in your heart, please do not use the pacifier as it makes me vulnerable to infection. LOVE you, mom."

\subsubsection{Change support process:}

Some tactic points were used to support the SM approach through:

- The village's pediatricians were requested to encourage breastfeeding over other substitutes while providing recommendations for the mothers as they are reported by mothers to be out of the influencers.

- Nurses were trained to help mothers on how to start and overcome the initial challenges of breastfeeding.

- distributing maternity messages for moms having android mobiles using WhatsApp application to provide them with tips on breastfeeding

- Mothers were introduced to the competition, those who answer all questions regarding breastfeeding wins a grand prize (breastfeeding pumper) and those who joined the competition received free breastfeeding covers

- To encourage mothers to breastfeed in public and increase breastfeeding times over non-breastfeeding times in outdoor areas, the breastfed women were provided by the breastfeeding cover (gown) to encourage mothers to breastfeed anywhere

- Mothers who shared their breastfeeding experience received breastfeeding covers as an incentive.

\subsection{Methods:}

A well-structured questionnaire was applied to the target groups through an interview to collect the nutritional data. The Centers for Disease Control (CDC) Infant Feeding Practices Questionnaire (23) was used to measure feeding practices throughout the first year of life. Food fed to the infant, including breast milk and infant formula, patterns of breastfeeding, solid food intake, and other complementary foods and liquids were recorded. Moreover, factors that may contribute to infant feeding practices and to breastfeeding success and other issues (food allergies, experiences with breast pumps and pacifiers) were also investigated. As part of the study, each mother received a number of self-report questionnaires at baseline, then monthly during a 1year follow-up after attending her three sessions.

Growth assessment was done for each infant aged less than 2 years twice (prior and after the interventions) using anthropometric parameters as follow:

The researchers, who are biological anthropologists, took anthropometric measurements on the infants, including weight, supine length, occipito-frontal circumference (head circumference $\mathrm{HC}$ ), and mid-upper arm 
circumference (MUAC) on the left hand. A flexible, non-stretchable measuring tape was applied to assess measurements to the nearest $0.1 \mathrm{~cm}$, following standardized research protocols and Quality control measures elaborated for the World Health Organization Multicenter Growth Reference Report (24).

Each infant was examined by the Holtain Body Composition Analyzer. The presence of any metallic element with or beside the participant should be avoided. The following parameters were derived : the percentage body fat (Fat \%: an estimate of the proportion of fat to the total body weight.), fat mass (FM: an estimate of the fraction of the total body weight that is adipose tissue), fat free mass (FFM: an estimate of the fraction of the total body weight that is not adipose tissue), Basal metabolic rate (BMR: to the setting of daily energy requirements and scientific diet guidance) $(25,26)$ and Total Body Water (TBW: an estimate of the fluid occupies intracellular and extracellular spaces, comprising about $0.6 \mathrm{~L} / \mathrm{kg}(63.3 \%)$ of body mass) for hydration assessment $(27,28)$.

Statistical methods

After data cleaning, all completed questionnaires were entered into the computer. Statistical analysis was done by using the Statistical Package of Social Software program (SPSS), version 20. The data were summarized using descriptive statistics where mean and standard deviation were used for quantitative variables. Number and percentage were used for qualitative values. Before and after the intervention, related indices were compared between the intervention and the control village with Pearson's Chi-square test $(\mathrm{X} 2)$ and $\mathrm{Z}$ test (for qualitative data) and with paired t-test (for continuous data between the pre and post interventions of growth parameters). A P-Value less than or equal to 0.05 was considered statistically significant

\section{Results}

After 28 months of the whole process of intervention, there was no one dropout regarding the targeted 200 mothers for assessment but with $(25.9 \%)$ drop out of infants. Sociodemographic characteristics of the direct beneficiaries between the intervention and the control villages were shown in table 1 . The differences between the characteristics of the participants within the two villages were not statistically significant suggesting that the participants within the two villages were balanced and comparable with each other. The age range of the mothers in the intervention village (18-30 years) was slightly insignificantly higher than that of the control village (20-30 years). The majority of mothers had middle school education; preparatory or secondary education ( $62.0 \%$ in the intervention village and $65.5 \%$ in the control village). The majority were married housewives and having an average of three children under 12 years old.

Table (1): Sociodemographic characteristics of the direct beneficiaries between the intervention and the control villages 


\begin{tabular}{|c|c|c|c|}
\hline Sociodemographic data & $\begin{array}{l}\text { Intervention village } \\
(n=200)\end{array}$ & $\begin{array}{l}\text { Control village } \\
(n=200)\end{array}$ & $P$ value \\
\hline \multicolumn{4}{|l|}{ Mother's age (years) } \\
\hline Range & $18-30$ & $20-30$ & \\
\hline Mean $\pm S D^{*}$ & $23.5 \pm 5.3$ & $24.5 \pm 4.8$ & 0.096 \\
\hline \multicolumn{4}{|l|}{ Mother Education n (\%) } \\
\hline Illiterate/ & $21(10.5 \%)$ & $17(8.5 .0 \%)$ & \\
\hline Read and Write/ Primary & $28(14.0 \%)$ & $32(16.0 \%)$ & \\
\hline Preparatory & $55(27.5 \%)$ & $71(35.5 \%)$ & \\
\hline Secondary & $69(34.5 \%)$ & $60(30.0 \%)$ & 0.356 \\
\hline University & $27(13.5 \%)$ & $20(10.0 \%)$ & \\
\hline \multicolumn{4}{|l|}{ Mother Occupation n (\%) } \\
\hline Housewife & $188(94 \%)$ & $177(88.5 \%)$ & \\
\hline Farmer & $6(3 \%)$ & $10(5 \%)$ & \\
\hline Worker & $2(1 \%)$ & $6(3 \%)$ & 0.246 \\
\hline Professional & $4(2 \%)$ & $7(3.5 \%)$ & \\
\hline \multicolumn{4}{|l|}{ Marital status n (\%) } \\
\hline Married & $194(97 \%)$ & $186(93 \%)$ & \\
\hline Widow & $5(2.5 \%)$ & $9(4.5 \%)$ & 0.136 \\
\hline Divorced & $1(.5 \%)$ & $5(2.5 \%)$ & \\
\hline \multicolumn{4}{|c|}{ Number of children in the house ( $<12$ years) } \\
\hline Range & $1-5$ & $1-5$ & 0.12 \\
\hline Mean $\pm S D^{*}$ & $2.8 \pm 2$ & $3.1 \pm 1$ & \\
\hline
\end{tabular}

Comparison of breastfeeding awareness, attitude, and practices indicators between the intervention and control villages among the direct beneficiaries, who are the mothers of infants till 2 years, was shown in Table 2. The results revealed that for all the studied indicators concerning awareness, attitude, and practices, the intervention group performed significantly better than those in the control group and before the intervention. Table 2 showed also the effect of the interventions on both the predominant breastfeeding under 6 months and those who are EBF; the formal one decreased significantly to half from 46.0-18\%. On the contrary, the proportion of children at 2 years who were EBF raised from 23.0-47\%. Continue breastfeeding during illness was also significantly increased after interventions from $77.9 \%$ to $87.9 \%$. The initial assessment for the 
studied women revealed many faulty practices as the consumption of liquids, solids, semi-solid, or soft food among children less than 6 months ( $46 \%$ ) and using the pacifier among children less than 2 years $(72.0 \%)$. These faulty practices were significantly corrected as a result of the interventions.

Table 2: Comparison of breastfeeding awareness, attitude and practices indicators between intervention and control villages among the direct beneficiaries before and after intervention 


\begin{tabular}{|c|c|c|c|c|c|}
\hline \multirow[t]{2}{*}{ Indicators } & \multicolumn{2}{|c|}{ Intervention village } & \multirow{2}{*}{$\begin{array}{l}\text { Control } \\
\text { village } \\
\mathrm{N}=200\end{array}$} & \multirow{2}{*}{$\begin{array}{l}\quad \text { P value of } Z \\
\quad \text { test } \\
\text { Pre vs Post } \\
\text { Intervention }\end{array}$} & \multirow{2}{*}{$\begin{array}{l}\text { P value of } \mathrm{Z} \\
\text { test } \\
\text { Post } \\
\text { Intervention } \\
\text { vs Control }\end{array}$} \\
\hline & $\begin{array}{c}\text { Pre- } \\
\text { intervention } \\
\mathrm{N}=200\end{array}$ & $\begin{array}{c}\text { Post- } \\
\text { intervention } \\
\mathrm{N}=200\end{array}$ & & & \\
\hline \multicolumn{6}{|c|}{ Awareness Indicators } \\
\hline $\begin{array}{l}\text { e of the meaning of exclusive } \\
\text { tfeeding }\end{array}$ & $96(48.0)$ & $148(74.0)$ & $87(43.5)$ & $<0.001^{* *}$ & $<0.001^{* *}$ \\
\hline $\begin{array}{l}\text { of the benefits of breastfeeding: } \\
2 \text { benefits } \\
\geq 3 \text { benefits }\end{array}$ & $\begin{array}{l}156(78.0) \\
44(22.0)\end{array}$ & $\begin{array}{l}90(45.0) \\
110(55.0)\end{array}$ & $\begin{array}{l}164(82.0) \\
36(18.0)\end{array}$ & $\begin{array}{l}<0.001^{* *} \\
<0.001^{* *}\end{array}$ & $\begin{array}{l}<0.001^{* *} \\
<0.001^{* *}\end{array}$ \\
\hline 1e of $\mathrm{X}^{2}$ & \multicolumn{3}{|c|}{$<0.001^{\mathrm{a}^{* *}} \quad<0.001^{\mathrm{b}^{* *}}$} & & \\
\hline $\begin{array}{l}\text { e of initiating breastfeeding } \\
\mathrm{g} \text { the first hour of delivery }\end{array}$ & 106(53.0) & $164(82.0)$ & $110(55.0)$ & $<0.001^{* *}$ & $<0.001^{* *}$ \\
\hline e of the meaning of colostrum & $166(83.0)$ & 186(93.0) & $157(78.5)$ & $<0.001^{* *}$ & $<0.001^{* *}$ \\
\hline $\begin{array}{l}\text { e of the benefits of colostrum } \\
2 \text { benefits } \\
\geq 3 \text { benefits } \\
\text { le of } \mathbf{X}^{2}\end{array}$ & $\begin{array}{l}170(85.0) \\
30(15.0) \\
\end{array}$ & $\begin{array}{l}84(42.0) \\
116(58.0) \\
1^{a^{* *}}\end{array}$ & $\begin{array}{l}175(87.5) \\
25(12.5) \\
01^{b * *}\end{array}$ & $\begin{array}{l}<0.001^{* *} \\
<0.001^{* *}\end{array}$ & $\begin{array}{l}<0.001^{* *} \\
<0.001^{* *}\end{array}$ \\
\hline \multicolumn{6}{|c|}{ Attitude Indicators } \\
\hline $\begin{array}{l}\text { tion of start weaning at age: } \\
\text { lonths } \\
\text { lonths } \\
\text { le of } \mathrm{X}^{2}\end{array}$ & $\begin{array}{l}76(38.0) \\
124(62.0) \\
\end{array}$ & $\begin{array}{l}14(7.0) \\
186(93.0) \\
1^{\mathrm{a}^{* *}}\end{array}$ & $\begin{array}{l}82(41.0) \\
118(59.0) \\
01^{b^{* *}}\end{array}$ & $\begin{array}{l}<0.001^{* *} \\
<0.001^{* *}\end{array}$ & $\begin{array}{l}<0.001^{* *} \\
<0.001^{* *}\end{array}$ \\
\hline $\begin{array}{l}\text { tion of continued breastfeeding: } \\
\text { rear } \\
\text { ind half years } \\
\text { rs } \\
\text { le of } \mathbf{X}^{2}\end{array}$ & $\begin{array}{l}94(47.0) \\
40(20.0) \\
66(33.0)\end{array}$ & $\begin{array}{l}60(30.0) \\
50(25.0) \\
90(45.0) \\
a^{* *}\end{array}$ & $\begin{array}{l}114(57.0) \\
34(17.0) \\
52(26.0) \\
01^{b * *}\end{array}$ & $\begin{array}{c}0.001^{* *} \\
0.230 \\
0.014^{*}\end{array}$ & $\begin{aligned}<0.001^{* *} \\
0.050 \\
<0.001^{* *}\end{aligned}$ \\
\hline \multicolumn{6}{|c|}{ Practices Indicators } \\
\hline $\begin{array}{l}\text { mption of liquids in the first day } \\
\text { very }\end{array}$ & $126(63.0)$ & $73(36.5)$ & $129(64.5)$ & $<0.001^{* *}$ & $<0.001^{* *}$ \\
\hline $\begin{array}{l}\text { mption of liquids among children } \\
\text { @ }\end{array}$ & $69(46.0)$ & $27(18.0)$ & $56(37.3)$ & $<0.001^{* *}$ & $<0.001^{* *}$ \\
\hline $\begin{array}{l}\text { mption of solid, semi-solid or soft } \\
\text { mong children }<6 \mathrm{~m} @ \text { : } \\
\text { Jnths } \\
\text { months } \\
\text { e of } \mathrm{X}^{2}\end{array}$ & $\begin{array}{l}33(22.0) \\
36(24.0)\end{array}$ & $\begin{array}{l}5(3.3) \\
22(14.7) \\
3^{* *}\end{array}$ & $\begin{array}{l}30(20.0) \\
26(17.3) \\
0.002^{b^{* *}}\end{array}$ & $\begin{array}{c}<0.001^{* *} \\
0.040^{*}\end{array}$ & $\begin{array}{c}<0.001^{* *} \\
0.529\end{array}$ \\
\hline $\begin{array}{l}\text { tfeeding and bottle feeding: } \\
\text { ive Breastfeeding } \\
\text { minant Breastfeeding } \\
\text { stfeeding \& Fluids) } \\
\text { feeding } \\
\text { (Breastfeeding and Bottle } \\
\text { g) } \\
\text { e of } \mathrm{X}^{2}\end{array}$ & $\begin{array}{l}46(23.0) \\
92(46.0) \\
16(8.0) \\
46(23.0)\end{array}$ & $\begin{array}{l}94(47.0) \\
36(18.0) \\
0(0.0) \\
70(35.0) \\
1^{a^{* *}}\end{array}$ & $\begin{array}{l}40(20.0) \\
74(37.0) \\
6(3.0) \\
80(40.0)\end{array}$ & $\begin{array}{l}<0.001^{* *} \\
<0.001^{* *} \\
<0.001^{* *} \\
<0.004^{* *}\end{array}$ & $\begin{array}{c}<0.001^{* *} \\
<0.001^{* *} \\
<0.001^{* *} \\
0.153\end{array}$ \\
\hline
\end{tabular}




\begin{tabular}{|c|c|c|c|c|c|}
\hline $\begin{array}{l}\text { tfeeding during illness }{ }^{\square} \text { : } \\
\text { tue breastfeeding } \\
\text { reastfeeding and bottle feeding } \\
\text { cial food } \\
\text { e of } \mathbf{X}^{2}\end{array}$ & $\begin{array}{l}148(77.9) \\
42(22.1)\end{array}$ & $\begin{array}{l}\text { 174(87.9) } \\
24(12.1) \\
3^{a^{*}}\end{array}$ & $\begin{array}{l}147(75.8) \\
47(24.2) \\
0.002^{b^{* *}}\end{array}$ & $\begin{array}{l}0.008^{* *} \\
0.008^{* *}\end{array}$ & $\begin{array}{l}0.002^{* *} \\
0.002^{* *}\end{array}$ \\
\hline pacifier & $144(72.0)$ & $57(28.5)$ & $134(67.0)$ & $<0.001^{* *}$ & $<0.001^{* *}$ \\
\hline
\end{tabular}

*significant $<0.05, \quad * *$ highly significant $<0.01$

${ }^{\mathbf{a}} \mathrm{P}$ value of $\mathrm{X}^{2}$ between before and after interventions, $\quad{ }^{\mathbf{b}} \mathrm{P}$ value of $\mathrm{X}^{2}$ between after interventions and control

@ Out of children aged from $6 \mathrm{~m}-<2 \mathrm{y}$ : in village before interventions $(\mathrm{n}=150)$, in village after interventions ( $\mathrm{n}=150)$, and in control village $(n=150),{ }^{\square}$ Out of mothers ever breastfed: in village before interventions $(n=190)$, in village after interventions $(n=198)$, and in control

As shown in Table 3, all targeted objectives as a result of the interventions were achieved regarding breastfeeding initiation during the first hour of delivery, EBF under 6 months, frequency of BF per Day which doubled their values at the baseline, except for continued breastfeeding till 2 years which showed some lag behind achievement. Moreover, $56.0 \%$ of children from $0-2$ years received breastfeeding when they got hungry or on-demand and this percent significantly raised to $69.0 \%$ as a result of the interventions with a significant difference from that of the control village for all indicators. 
Table 3

Target versus achievements of breastfeeding practices' indicators among the direct beneficiaries in the intervention village before and after the intervention.

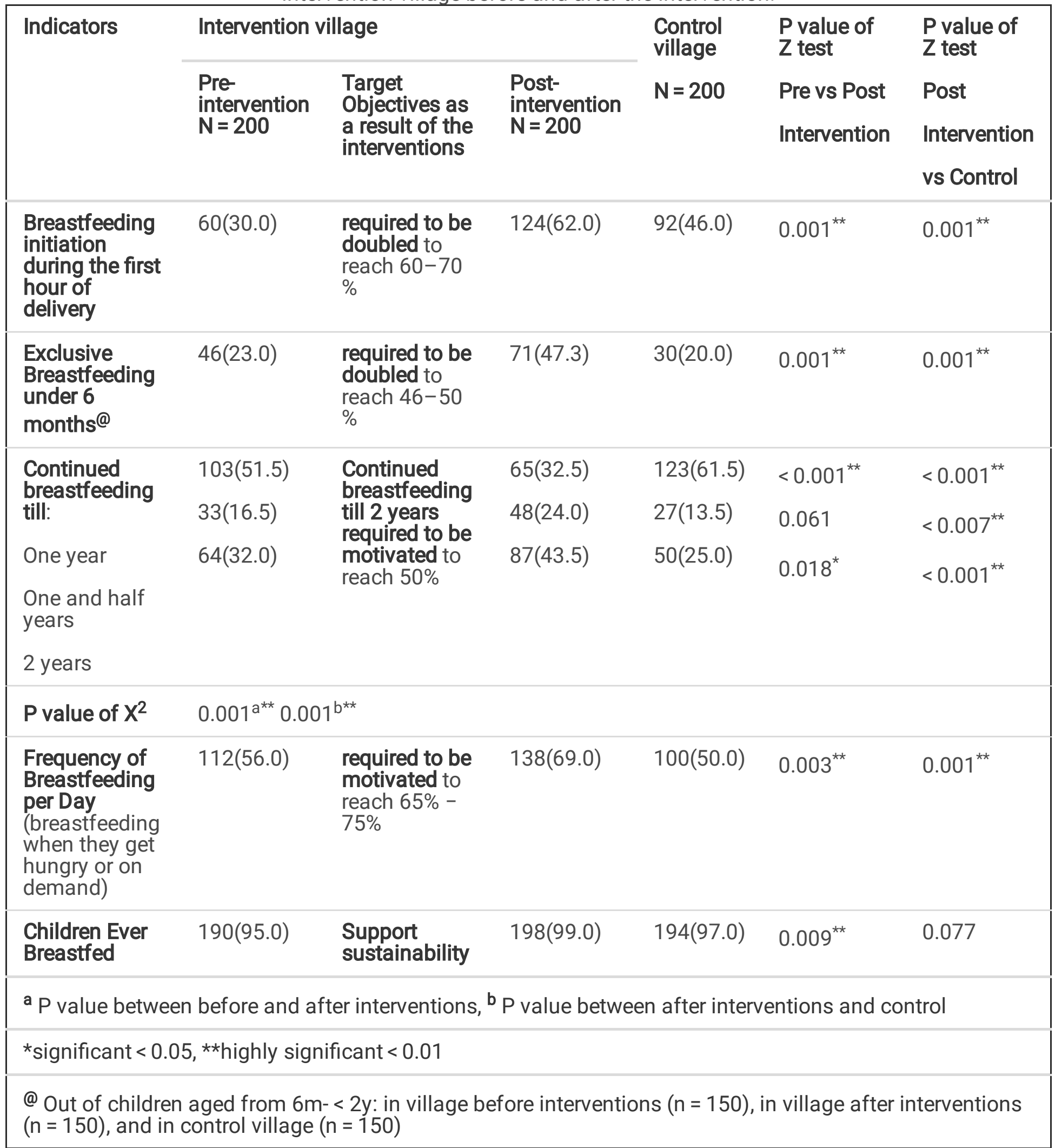

Table 4 presented the influence of mothers' engagement in the interventions on the improvement of different breastfeeding indicators. The majority of indicators showed significant improvement with three or more time attendance than those who attended once or two times. The impact of engagement for three times or more was most obvious for the breastfeeding initiation (80.0\%) followed by the proportion of mothers who 
continued breastfeeding till 2 years (70.1\%), EBF under 6 months (69.0\%), breastfeeding their infants when they get hungry or on-demand (68.8\%).

Table 4

Impact of engagement in the interventions on breastfeeding practice among the direct beneficiaries in the intervention village before and after the intervention

\begin{tabular}{|c|c|c|c|}
\hline Variables & $\begin{array}{l}\text { Two times } \\
\text { of } \\
\text { attendance }\end{array}$ & $\begin{array}{l}\text { Three or more } \\
\text { times of } \\
\text { attendance }\end{array}$ & $\begin{array}{l}P \\
\text { value }\end{array}$ \\
\hline $\begin{array}{l}\text { Breastfeeding initiation }(n=124) \text { : Proportion of children born } \\
\text { in the last } 24 \text { months who were put to the breast within one } \\
\text { hour of birth }\end{array}$ & 24(19.4) & $100(80.6)$ & $0.001^{* *}$ \\
\hline $\begin{array}{l}\text { Exclusive Breastfeeding under } 6 \text { months }(n=71) \text { : Proportion } \\
\text { of infants } 0-5 \text { months of age who are fed exclusively with } \\
\text { breast milk @ }\end{array}$ & $22(31.0)$ & $49(69.0)$ & $0.001^{* *}$ \\
\hline Continued breastfeeding till one year $(n=65)$ & $40(61.5)$ & $25(38.5)$ & $0.004^{\star *}$ \\
\hline Continued breastfeeding till one and half years $(n=48)$ & $34(70.8)$ & $14(29.2)$ & $0.001^{* *}$ \\
\hline Continued breastfeeding till 2 years $(n=87)$ & $26(29.9)$ & $61(70.1)$ & $0.001^{\star \star}$ \\
\hline $\begin{array}{l}\text { Frequency of Breastfeeding per Day (breastfeeding when they } \\
\text { gets hungry or on demand) }(n=138)\end{array}$ & $43(31.2)$ & $95(68.8)$ & $0.001^{* *}$ \\
\hline *significant $<0.05$, **highly significant $<0.01$ & & & \\
\hline
\end{tabular}

Comparison of the growth indices among the children of direct beneficiaries in the intervention village pre and post-intervention were shown in table 5. At the initial assessment 234 infants aged 6-24 months (117 boys and 117 girls) were targeted. After the intervention 180 infants aged 6-24 months (84 boys and 96 girls) were evaluated, with $55.6 \%$ of the infants involved in both the assessment and evaluation (50 boys and 50 girls). Improvement was observed significantly for the majority of the growth parameters as a result of the interventions. Growth indices including weight-for-age Z score (<-2 SD) as an indicator for underweight, weight-for-height Z score (<- 2 SD) as an indicator for wasting; and weight-for-age Z score $(>+2$ SD) as an indicator for overweight/ obesity, were presented in table 5. It was obvious that: before the intervention phase, during the first 2 years of life, girls recorded to be underweight were higher than boys however, significant improvement as a result of interventions were observed. The same significance recorded in the total sample. Moreover, regarding weight-for-height $Z$ score $(<-2 S D)$ as an indicator for wasting, $(>+2$ SD) as an indicator for overweight/obese: It was observed that after intervention wasting disappeared completely in both boys and girls. The same results recorded for obesity in girls with a highly significant difference $(P=0.000)$, but boys showed insignificant improvement. For overweight, girls showed also insignificant improvement. Concerning other growth parameters, it was noticed a highly significant difference regarding MUAC as a result of the intervention. Meanwhile, both the $\mathrm{HC}$ and MUAC were within the normal ranges before and after the interventions. The body composition parameters showed significant decrease in both FM and fat \% and a significant increase in FFM, TBW, and BMR as a result of the intervention. 
Table (5): Comparison of growth indices between the children of direct beneficiaries in the intervention village pre and post the intervention

\begin{tabular}{|c|c|c|c|}
\hline Growth indices & $\begin{array}{l}\text { Pre } \\
(\mathrm{N}=117)\end{array}$ & $\begin{array}{l}\text { Post } \\
(\mathrm{N}=84)\end{array}$ & $\mathbf{P}$ \\
\hline \multicolumn{4}{|l|}{ WAZ (Underweight) } \\
\hline Boy n (\%) & $12(10.3)$ & $6(7.1)$ & 0.447 \\
\hline Girl n (\%) & $78(66.7)$ & $18(18.8)$ & 0.000 \\
\hline Total n (\%) & $90(38.5)$ & $24(13.3)$ & 0.000 \\
\hline \multicolumn{4}{|l|}{ WLZ (Wasting) } \\
\hline Boy n (\%) & $5(4.3)$ & $0(0.0)$ & 0.55 \\
\hline Girl e n (\%) & $3(2.7)$ & $0(0.0)$ & 0.114 \\
\hline Total n (\%) & $8(3.4)$ & $0(0.0)$ & 0.012 \\
\hline \multicolumn{4}{|l|}{ WLZ (Overweight) } \\
\hline Boy n (\%) & $28(23.9)$ & $30(35.7)$ & 0.069 \\
\hline Girl n (\%) & $28(23.9)$ & $18(18.8)$ & 0.363 \\
\hline Total n (\%) & $56(23.9)$ & $49(26.7)$ & 0.447 \\
\hline \multicolumn{4}{|l|}{ WLZ (Obese) } \\
\hline Boy n (\%) & 16(13.7) & $6(7.1)$ & 0.144 \\
\hline Girl n (\%) & $18(15.4)$ & $0(0)$ & 0.000 \\
\hline Total n (\%) & $34(14.5)$ & $6(3.3)$ & 0.000 \\
\hline \multicolumn{4}{|l|}{ Body circumferences } \\
\hline $\mathrm{HC}(\mathbf{c m})$ Mean $\pm S D * \nabla$ & $47.20 \pm 4.29$ & $48.68 \pm 2.76$ & 0.113 \\
\hline $\operatorname{MUAC}(\mathbf{c m})$ Mean $\pm S D * \psi$ & $15.80 \pm 2.97$ & $18.77 \pm 2.22$ & $0.000 * *$ \\
\hline \multicolumn{4}{|c|}{ Body composition parameters } \\
\hline TBW Mean \pm SD* & $8.44 \pm 4.46$ & $12.92 \pm 4.30$ & 0.001 ** \\
\hline FFM Mean $\pm S D^{*}$ & $8.71 \pm 4.41$ & $11.09 \pm 1.80$ & $0.010 *$ \\
\hline FM Mean $\pm S D^{*}$ & $6.04 \pm 7.33$ & $3.10 \pm 1.11$ & $0.027^{*}$ \\
\hline Fat\% Mean $\pm S D *$ & $32.07 \pm 19.7$ & $21.75 \pm 5.96$ & $0.003^{* *}$ \\
\hline BMR Mean $\pm S D^{*}$ & $2878.47 \pm 504.67$ & $3589.93 \pm 628.56$ & $0.000 * *$ \\
\hline
\end{tabular}

WAZ = Weight-for-age $Z$ score $(<-2$ SD) as an indicator for underweight. 
WLZ = Weight-for- Length Z score ( $<-2 \mathrm{SD})$ as an indicator for wasting; $(>+2 \mathrm{SD})$ as an indicator for overweight/ obese.

$\bigotimes$ Normal range of $\mathrm{HC}(-2 \mathrm{SD}$ TO $2 \mathrm{SD})=37.6-47.2$, Median $=47.05$

$\Psi$ Normal range of MUAC $(-2$ SD TO 2 SD $)=12.4-15.7$, Median $=13.8$

$F M=$ fat mass, $F F M=$ fat free mass, $T B W=$ total body water, $B M R=$ basal metabolic rate,

\section{Discussion}

The first 2 years of life are crucial as during this period, the body lays the foundation for the future growth and development of a child. Any nutritional deficiencies during this time can be manifested in the form of impaired cognitive development, and physical growth $(29,30)$ compromised educational achievement, and ultimately low economic productivity later in life (31). Furthermore, the role of breastfeeding in boosting child immunity was evident and the weaknesses of eating habits decreased child immunity and considered as an entry point to COVID-19 (32) and as a trigger for increasing phobia (33)

Optimization of breastfeeding practices could reduce high mortality rates in children younger than 5 years. Enhancing breastfeeding practices is a worldwide concern that was included among the Millennium Development Goals developed by the World Health Organization in the last decade $(34,35)$. Investing in children's growth and development could theoretically drive the transformation endeavored for by 2030 under SDG3, i.e. good fitness and wellbeing for all $(36,37)$.

The present study employed social marketing approach to reduce physical barriers to exclusive breastfeeding, to be continued for infants up to two years of age, and to facilitate for the mothers to breastfeed in public and making it easier, more convenient, and appropriate for all women. The current study was conducted in phases; formative research was conducted to understand the motives and barriers for breastfeeding and detected obstacles and factors contributing to the declining of breastfeeding practices.

The intervention phase aimed at altering behaviors with respect to social norms of the mothers; included pregnant women and mothers of infants up to 2 years of age as direct beneficiaries and women in their childbearing period as indirect beneficiaries. Initiating breastfeeding early within one hour of birth, encouragement of breastfeeding exclusively for six months, and continuing for up to 24 months were also among the goals of this phase. Moreover, encouragement of responsive feeding of mothers' to their babies' cues of hunger and satiety.

Breastfeeding judgments are influenced by a variety of variables, such as experience, perception, behaviors, and motivation (35). Women received considerable encouragement by adopting positive mindset, which was reflected in their intentions and actions. When compared to pre-intervention and the control rural area, knowledge of the nature of exclusive breastfeeding and that colostrum is the first breast milk that includes antibodies to protect the infant from diseases increased dramatically after the intervention. Breastfeeding initiation reflected this increase in awareness and intuition. The intervention doubled the number of mothers who began breastfeeding within the first hour of delivery and those who exclusively breastfed their infants for 
6 months. Increased understanding of behaviors related to breastfeeding practices was found to be assuring factor for enhancing breastfeeding in Jordan, according to recent Eastern Mediterranean studies $(35,38)$.

Both early breastfeeding initiation and exclusive breastfeeding are common practices in some Arab countries even without promotion interventions. For example, the prevalence in Abu Dhabi was $72.6 \%$ for early breastfeeding initiation and $42.0 \%$ for exclusive breastfeeding (38) and $55.9 \%$ of them had practiced EBF for at least six months (39). These figures are comparable to our findings which showed significant improvement after the interventions (from $30 \%$ to $62.0 \%$ for the early breastfeeding initiation and from $23-47.3 \%$ for EBF less than 6 months). The World Health Organization considers early initiation of breastfeeding rates ranging from $50 \%$ to $89 \%$ and exclusive breastfeeding rates above $60 \%$ as good and as global targets set to meet by 2030 (40). This indicates that the improvement in the percentage of early initiation of breastfeeding falls within the category of WHO-recommended as good rate but we still have to work for that of EBF less than 6 months to reach the target or even beyond.

The low percentages for the performance of the previously mentioned two indicators done before the intervention and in the control villages were due to cultural perceptions and misinformation. Cultural factors were also reported by many studies in the Middle East countries; in which EBF's primary barriers were women's perceptions of insufficient breast-milk, beliefs about infant thirst, and need for water (41) or due to receiving conflicting advice such as discouraging formula but encouraging herbal drinks (42). Meanwhile, in different societies around the world women's breastfeeding practices were commonly affected by others' comments resulting in introducing complementary foods before six months of age $(42,43)$.

Barriers can be highly variable across communities, contributing to local variation in EBF practices. Our study reported the barriers behind not giving colostrum to babies after the birth. It was not only because of the lack of awareness about the advantages of colostrum's feeding but also because of some culture and beliefs. One of these beliefs is that "women who delivered by cesarean section (CS), her breast milk got spoiled due to the anesthesia and must not breastfeed except after 2 or 3 days". This belief is enforced by most nurses and hospital staff who encourage feeding the neonate glucose or artificial milk on the first day or sometimes throughout the mother's stay at the hospital.

Another belief is that "giving liquid to the babies less than 6 months is essential to relief baby colic and constipation". Out of the culture barriers reported by the mothers of the current study against EBF before the interventions were "breastfeeding should be done only inside the home (no breastfeeding outdoors)", "Good breastfeeding depends on the size of the breast", "Mothers should not breastfeed their children during the night to save the milk for the day and for not to cause any stomach troubles for their babies". The improvement of these two indicators occurred after the intervention point out the success of the used SM approach. Our study, through the use of SM, could have overcome the barriers against not giving colostrum to babies after birth or to sustained EBF till 6 months of age.

Responsive feeding of mothers' to their babies' cues of hunger and satiety raised from $31.2 \%$ to $68.8 \%$ as a result of this study interventions. This figure was slightly lower than that reported by two others Egyptian studies $(44,45)$ who reported three quarters and more mothers giving BF on demand. The currently reported low percentage of responsive feeding of mothers' to their babies' cues of hunger and satiety before the 
interventions could be attributed to the same reasons they reported to be behind the option for not to Exclusive breastfeed their infants under 6 months of age.

The current findings of the present study thus support the need for community-based interventions to overcome the culture and local barriers. Moreover, the successful role of the community-based behavioral change interventions in many health promotion programs were evident in Egypt; to overcome health barriers for endemic diseases $(46-52)$, for maternal health promotion $(53,54)$, child health promotion $(55)$ and improvement of sanitation practices (56).

Among the improved Indicators as a result of the interventions, but needs more attention about, is the intention of continued breastfeeding till 2 years. Although it varied significantly from its figure before the intervention (32\%) and versus that of the control village (25\%), yet continuation of breast feeding till 24 months was sustained by less than half of the participants (45\%). Meanwhile, this finding was more than that reported in the United Arab Emirates (U.A.E.) by a recent study in which only $28.7 \%$ of mothers were planning to continue breastfeeding for the child $\geq 24$ months (38).

The strong social support that was applied through the use of SM approach motivated not only the direct beneficiaries but also their mothers, mothers-in-law and their relatives. This support was one of the major reasons behind the great improvement achieved for the majority of the indicators to more doubling its value before the intervention. Moreover, the faulty practices as using the pacifier among infants less than 2 years, consumption of liquids, solid, semi-solid or soft food among infants less than 6 months, and stopping breastfeeding during illness were high initially (72 \%, $46 \%$ and $22.1 \%$ respectively). However, as a result of interventions, all these defective practices were significantly corrected and their percentages lowered to be 28.5 $\%, 18 \%$ and $12.1 \%$ respectively. The use of a pacifier was found to be a predictor of early termination of EBF at discharge (57-59). This finding reflects the importance of the use of SM approach during counseling and education on BF practices in local communities.

Influence of mothers' engagement in the interventions' attendance on the improvement of different BF indicators was obvious for all the studied indicators and was comparable to the study done by (60) indicating that knowledge plays an important role in deciding and making informed decisions regarding BF practices.

Anthropometry has become a practical tool for evaluating the nutritional status of populations, particularly of children in developing countries. Nutritional status is the best indicator of the global well-being of children (61). Z-scores have been used in the present study to assess growth in children. It is widely recognized as the best method for analysis and presentation of anthropometric data (62). Feeding of infants with different milk formulas and early introduction of solid foods were important factors of early life stages that favor the development of obesity in children (63). In the first 1000 days of life, boys reported having a higher prevalence of both wasting and stunting (64).

In the present study, before interventions, girls recorded underweight results over boys which disappeared and significantly improved as a result of the interventions. Discussion with the targeted mothers to detect motives for change revealed that baby boy is considered a priority for feeding and nursing to make him strong and healthy (63). 
This wrong cultural belief was targeted during the study interventions. A national study in Egypt for the determinants of stunting reported the importance of breastfeeding to have normal weight children at their school-age (32)

Wasting is an acute malnutrition condition and manifests when there is an absolute shortage of food (65). The present study recognized well the critical importance of addressing wasting, where the low weight-forlength Z score as an indicator for wasting was disappeared completely in both boys and girls as a result of the intervention. This finding is confirmed by the highly significant difference for MUAC values, as our study followed the United Nations community-based approaches for improving coverage of the treatment of wasting which includes the use of MUAC to aid in the timely identification of severe acute malnutrition (66). Childhood wasting requires urgent attention from policy-makers and program implementers to reduce and maintain its percentage among young children at a level less than $5 \%$ to achieve the sixth goal of Global nutrition targets 2025 for improvements of their nutritional status (67).

During infancy, adipose tissue is growing by a combination of an increase in fat cell size (to a lesser extent) and (above all) the number of these cells (68). The first 6 months of life are a critical window for adiposity programming, which may have major implications for primary health care; Infants with a rapid increase in FM\% had a higher path of FM\% and FM index during the first 2 years of life (69). The risk for adiposity and cardiovascular diseases at age 21 years and beyond is associated with the rapid increase of weight detected in early life (70).

Accurate measures of obesity require more detailed indicators of true health status such as FM, Fat Mass percentage (FM \%), and fat-free mass (FFM) (71). The current study focused on these body composition measures. Few studies took these measurements into consideration, where infancy represents a critical period of life (72). The current study revealed a significant decrease in FM and fat \% as a result of the intervention, proving the considerable benefits of breastfeeding to infants.

Our present study showed a significant increase in basal metabolic rate (BMR) which of course not only because of the interventions related to the promotion for breastfeeding but also to the proper weaning and counteracting against the detected feeding barriers through the SM approach. We have been ensured appropriate quantity of food calories required for a healthy life to be provided to infants. In the body, FFM is considered the metabolically active tissue. In the current study, there was a significant increase in FFM as a result of the intervention.

\section{Conclusions And Recommendations}

Application of the current study results will help in putting Egypt on the track to accomplish WHO global nutrition targets by 2025. Our study intervention program made the mothers more aware of how to provide adequate caring and feeding practices to their children's e.g. exclusive breastfeeding or good quantity and quality of complementary food. Through the use of the SM approach, the myths surrounding complementary feeding and causing obesity or overweight were tackled. This was reflected in obese girls who were improved significantly as evidenced by 
Weight-for- Length Z score (WLZ). In fact, breast milk, although has a high nutritive value, has also low caloric value so, exclusive breastfeeding could be considered as the appropriate food to lower the risk for childhood obesity.

The cultural aspect of the community has been concerned during this survey for breastfeeding practices during the first two years of life. Current results can be considered as good indicators for the success of the use of social marketing principles. This program must be continued on a wider scale in different communities with similar contexts. Special interest should be directed to girls early in life even before being married, to give them advice about good and healthy patterns of feeding lifestyle.

Strength Of The Study

This study took into consideration two core steps to make the use of social marketing impactful on promoting breastfeeding practices and on infant growth. These two core steps were building evidence through gathering and analyzing data in a scientifically appropriate way, measuring impact, evaluating the effect of the social marketing, monitoring and evaluating its output, outcome, and impact.

Our social marketing plan responded to local needs, clarified how to act on the behavior pathway through providing motives that worked as enablers contributing to the targeted behavior change goal to be then translated into changes in the daily and regular practice of mothers

\section{Limitation of the study}

Difficulty in accessing infants 6-24 months in the control village resulted in limiting the measurements of the growth indices for the infants within the control village.

\section{Abbreviations}

SM: social marketing

EBF: exclusive breastfeeding

SDGs: Sustainable Development Goals

EDHS: Egypt Demographic and Health Survey

WHO: World Health Organization

CHWs: Community Health Workers

KPIs: key performance indicators

ORS : Oral Rehydration Salts

CDC: Centers for Disease Control

HC: head circumference 
MUAC: mid-upper arm circumference

FM: fat mass

FFM: free fat mass

BMR: Basal metabolic rate

TBW: Total Body Water

CS: cesarean section

U.A.E: .United Arab Emirates

FM \%: Fat Mass percentage

WLZ: Weight-for- Length Z score

WAZ : Weight-for-age Z score

\section{Declarations}

\section{Ethics approval and consent to participate}

The study was compiled with the International Ethical Guidelines for Biomedical Research Involving Human Subjects (73). The Medical Research Ethics Committee of the National Research Centre cleared the study protocol (Ethical approval number: 16250). Written informed consent was obtained from all the women enrolled in the study. To respect confidentiality, infants were identified by a serial number and the information at the individual level was kept strictly confidential. From the ethical point of view; after completion of the evaluation, a nutritional awareness conference was done in the control village and the educational materials were distributed to the targeted groups.

\section{Consent for publication}

Not applicable

\section{Availability of data and materials}

The datasets used and/or analysed during the current study are available from the corresponding author on reasonable request.

\section{Competing interests}

All authors report no conflict of interest. "No financial or non-financial benefits have been received or will be received from any party related directly or indirectly to the subject of this manuscript.

\section{Funding}


No fund received.

\section{Authors' contributions}

AMM was responsible for conceptualization, data curation, methodology, project administration, supervision, and review \& editing.

WAB helped in data curation, visualization, investigation, software, reviewing, and editing.

GAA aided in data curation, formal analysis, software, validation, and visualization.

SFS was taking a part in data curation, visualization, investigation, and software.

IRE, MHA, HAA, WY, AAG, GAE, \& DEA were all in charge of data curation, investigation, and software.

NA I was responsible for investigation, supervision, and project administration.

SAE \& N E H supported in supervision, formal analysis, software, validation, and visualization

SMA, WAK \& EMS were taking care of investigation, supervision, and project administration

RASE, IHK helped in taking care of data curation, investigation, and supervision

EMA aided in data curation and Investigation

MAM assisted in the review and editing of the article.

WSM was participating in the data curation, formal analysis, investigation, software, validation, visualization in addition to writing the original draft.

All authors read and approved the final manuscript

\section{Acknowledgments}

The authors are grateful to the staff members of the community-based association of the rural villages and the health staff of the village rural health units of the Ministry of health and population in Egypt who were enrolled in the study for their collaborative effort to promote breastfeeding at a community level. We gratefully acknowledge all the participants for their acceptance and participation in the current study.

\section{References}

1. Counseling of Women to Improve Breastfeeding Practices. Geneva: World Health Organization; 2018. Executive Summary. Available from: https://www.ncbi.nlm.nih.gov/books/NBK539319/

2. Victora CG, Bahl R, Barros AJ, França GV, Horton S, Krasevec J, Murch S, Sankar MJ, Walker N, Rollins NC, Group TL. Breastfeeding in the 21st century: epidemiology, mechanisms, and lifelong effect. The Lancet. 2016 Jan 30;387(10017):475-90. 
3. Abdel-Rahman ME, El-Heneidy A, Benova L, Oakley L. Early feeding practices and associated factors in Sudan: a cross-sectional analysis from multiple Indicator cluster survey. Int Breastfeed J. 2020 Dec;15:11.

4. Benova L, Siddiqi M, Abejirinde IO, Badejo O. Time trends and determinants of breastfeeding practices among adolescents and young women in Nigeria, 2003-2018. BMJ global health. 2020 Aug 1;5(8):e002516.

5. WHO, UNICEF, The extension of the 2025 maternal, infant and young child nutrition targets to 2030. Geneva: World Health Organization; 2018.

6. El-Din EM, Elabd MA, Nassar MS, Metwally AM, Abdellatif GA, Rabah TM, Shalaan A, Shaaban SY, Kandeel W, El Etreby LA, Al-Tohamy M. The interaction of social, physical and nutritive factors in triggering early developmental language delay in a sample of Egyptian children. Open Access Maced J Med Sci. 2019 Sep 15;7(17):2767.

7. El Din EM, Rabah TM, Metwally AM, Nassar MS, Elabd MA, Shalaan A, Kandeel W, El Etreby LA, Shaaban SY. Potential Risk Factors of Developmental Cognitive Delay in the First Two Years of Life. Open Access Maced J Med Sci.2019

8. Metwally AM, Salah El- Din EM, Shehata MA, Shaalan A, El Etreby LA, Kandeel WA, Sanaa Y. Shaaban SY and Rabah TM (2016) Early Life Predictors of Socio-Emotional Development in a Sample of Egyptian Infants. PLoS ONE 11(7): ISSN 1932-6203

9. Alzaheb RA. A review of the factors associated with the timely initiation of breastfeeding and exclusive breastfeeding in the Middle East. Clin Med Insights Pediatr. 2017;11:1179556517748912

10. Chehab RF, Nasreddine L, Zgheib R, Forman MR. Exclusive breastfeeding during the 40-day rest period and at six months in Lebanon: a cross-sectional study. International Breastfeeding Journal. 2020 Dec;15:1-0.

11. El-Zanaty, Fatma and Ann Way. 2009. Egypt Demographic and Health Survey 2008. Cairo, Egypt: Ministry of Health, El-Zanaty and Associates, and Macro International

12. Ministry of Health and Population [Egypt], El-Zanaty and Associates [Egypt], and ICF International. Egypt Demographic and Health Survey 2014. Cairo, Egypt and Rockville, Maryland, USA: Ministry of Health and Population and ICF International, 2015

13. Kandeel WA, Rabah TM, Zeid DA, El-Din EMS, Metwally AM, Shaalan A, El Etreby LA, Shaaban SY. Determinants of Exclusive Breastfeeding in a Sample of Egyptian Infants. Open Access Maced J Med Sci. 2018 Oct 25; 6

14. Protecting, promoting and supporting breastfeeding in facilities providing maternity and newborn services. Geneva: World Health Organization; 2017

15. World Health Organization. Proposed global targets for maternal, infant and young child nutrition summary of main issues raised and who responses. World Health Organization discussion paper 2012.

16. Sriraman NK, Kellams A. Breastfeeding: What are the Barriers? Why Women Struggle to Achieve Their Goals. J Womens Health (Larchmt). 2016 Jul;25(7):714-22.

17. McFadden A, Siebelt L, Marshall JL, Gavine A, Girard LC, Symon A, MacGillivray S. Counselling interventions to enable women to initiate and continue breastfeeding: a systematic review and metaanalysis. Int Breastfeed J. 2019 Dec;14(1):1-9. 
18. Lindenberger JH, Bryant CA. Promoting breastfeeding in the WIC program: a social marketing case study. Am. J. Health Behav. 2000 Jan 1;24(1):53-60.

19. Firestone R, Rowe CJ, Modi SN, Sievers D. The effectiveness of social marketing in global health: a systematic review. Health policy and planning. 2017 Feb 1;32(1):110 - 24.

20. Fleiss J L, Levin B, Paik MC. Statistical Methods for Rates and Proportions. Third Edition. John Wiley \& Sons. 2003New York.

21. Newcombe RG. Two-sided confidence intervals for the single proportion: comparison of seven methods. Statistics in medicine. 1998 Apr 30;17(8):857-72.

22. WHO, early initiation of breastfeeding to promote exclusive breastfeeding: WHO; 2019. http://www.who.int/elena/titles/early_breastfeeding/en/. Accessed 2 Mar 2020.

23. Centers for Disease Control and Prevention. Infant Feeding Practices Study II and its year six follow-up. Atlanta, GA: Centers for Disease Control and Prevention; 2014. http://www.cdc.gov/breastfeeding/data/ifps/index.htm.

24. de Onis M, Onyango AW, Van den BJ, Chumlea WC, Martorell R. Measurement and standardization protocols for anthropometry used in the construction of a new international growth reference. Food Nutr Bull. 2004; 25:S27-S36.

25. Zhang J, Tian Z, Tan H. [Research progress in measurement of human basal metabolic rate]. Zhong Nan Da Xue Xue Bao Yi Xue Ban. 2018 Jul 28;43(7):805-810.

26. Soha M Abd El-Dayem, Sahar A El-Masry, Hamed Elghawaby, Farid Gamil Amin, Ibrahim A Ibrahim. Total and Intra-Abdominal Fat Distribution in Obese Adolescents Using Different Techniques: Anthropometry, BIA and CT. Maced. J. Med. Sci. 2012 Oct 15; 5(3):269-274.

27. Armstrong LE, Kenefick RW, Castellani JW, et al. Bioimpedance spectroscopy technique: intra-, extracellular and total body water. Med Sci Sports Exerc. 1997; 29:1657-1663.

28. Lawrence E. Armstrong, PhD, FACSM, Hydration Assessment Techniques, Nutrition Reviews, Volume 63, Issue suppl_1, June 2005, Pages S40-S54

29. Metwally AM, El-Sonbaty M, El Etreby LA, El-Din EMS, Hamid NA, Hussien HA, Hassanin A, Monir ZM. Stunting and its Determinants among Governmental Primary School Children in Egypt: A School-based Cross-sectional Study. Open Access Maced J Med Sci [Internet]. 2020 Sep.15;8(B):650-7.

30. Metwally AM, El-Sonbaty MM, El Etreby LA, Salah El-Din EM, Abdel Hamid N, Hussien HA, Hassanin AM, Monir ZM. Impact of National Egyptian school feeding program on growth, development, and school achievement of school children (2020): World Journal of Pediatrics ISSN 1708-8569 World J Pediatr 2020, vol., 16 no,4: 393-400 DOI 10.1007/s12519-020-00342-8.

31. Ariff S, Saddiq K, Khalid J, Sikanderali L, Tariq B, Shaheen F, Nawaz G, Habib A, Soofi SB. Determinants of infant and young complementary feeding practices among children 6-23 months of age in urban Pakistan: a multicenter longitudinal study. BMC nutr. 2020 Dec;6(1):1-9.

32. Metwally AM, Shaaban FA, Mahmoud WS, Salah EM, El-Sonbaty MM, Hussien HA, Hamid NA, El Etreby LA, Hassanin A, Monir Z. Vulnerability and Weaknesses of Eating Habits of Overweight School Children as an Entry Risk for COVID-19. Open Access Maced J Med Sci [Internet]. 2020Aug.30 [cited 20200ct.18];8(T1):158-66. 
33. Metwally AM, El-Sonbaty MM, Abdellatif GA, El-Etreby LA, Elsayed H, Elsheshtawy E, Elsaeid A, Ibrahim NA. Common Phobias among Egyptian Primary Schoolchildren: An Emergency Trigger for Panic Disorder due to Corona Pandemic. Open Access Maced J Med Sci [Internet]. 2020May11 [cited 2020Jul.2];8(T1):3-11.

34. Yotebieng M, Labbok M, Soeters HM, Chalachala JL, Lapika B, Vitta BS, Behets F. Ten Steps to Successful Breastfeeding programme to promote early initiation and exclusive breastfeeding in DR Congo: a clusterrandomised controlled trial. Lancet Glob Health. 2015 Sep;3(9):e546-55. doi: 10.1016/S2214109X(15)00012-1. Epub 2015 Aug 2. PMID: 26246225.

35. Khasawneh W, Kheirallah K, Mazin M, Abdulnabi S. Knowledge, attitude, motivation and planning of breastfeeding: a cross-sectional study among Jordanian women. Int Breastfeed J. 2020 Dec;15(1):1-9.

36. UN. Helping governments and stakeholders make the SDGs a reality. https://sustainabledevelopment.un.org/. Accessed 7 Jan 2020

37. Taneja S, Chowdhury R, Dhabhai N, Mazumder S, Upadhyay RP, Sharma S, Dewan R, Mittal P, Chellani H, Bahl R, Bhan MK. Impact of an integrated nutrition, health, water sanitation and hygiene, psychosocial care and support intervention package delivered during the pre-and peri-conception period and/or during pregnancy and early childhood on linear growth of infants in the first two years of life, birth outcomes and nutritional status of mothers: study protocol of a factorial, individually randomized controlled trial in India. Trials. 2020 Dec 1;21(1):127.

38. Al Ketbi MI, Al Noman S, Al Ali A, Darwish E, Al Fahim M, Rajah J. Knowledge, attitudes, and practices of breastfeeding among women visiting primary healthcare clinics on the island of Abu Dhabi, United Arab Emirates. Int Breastfeed J. 2018 Dec;13(1):1-4.

39. Dukuzumuremyi JP, Acheampong K, Abesig J, Luo J. Knowledge, attitude, and practice of exclusive breastfeeding among mothers in East Africa: a systematic review. International Breastfeeding Journal. 2020 Dec;15(1):1-7.

40. World Health Organization \& LINKAGES. (2003). Infant and young child feeding: a tool for assessing national practices, policies and programmes. World Health Organization.

41. Bhattacharjee NV, Schaeffer LE, Marczak LB, Ross JM, Swartz SJ, Albright J, Gardner WM, Shields C, Sligar A, Schipp MF, Pickering BV. Mapping exclusive breastfeeding in Africa between 2000 and 2017. Nature medicine. 2019 Aug;25(8):1205-12.

42. Murad A, Renfrew MJ, Symon A, Whitford H. Understanding factors affecting breastfeeding practices in one city in the Kingdom of Saudi Arabia: an interpretative phenomenological study. Int Breastfeed J. 2021 Dec;16(1):1-9.

43. Ekelund L, Gloppen I, Øien T, Simpson MR. Duration of breastfeeding, age at introduction of complementary foods and allergy-related diseases: a prospective cohort study. Int Breastfeed J. 2021 Dec;16(1):1-4.

44. Ghwass MM, Ahmed D. Prevalence and predictors of 6-month exclusive breastfeeding in a rural area in Egypt. Breastfeeding medicine. 2011 Aug 1;6(4):191-6.

45. Hassan SK, Abdelwahed WY. Knowledge \& practices of exclusive breastfeeding in Fayoum, Egypt. Egyp J Commun Med. 2015 Jan;33:61-77.

46. Metwally AM, Soliman M, Abdelmohsen AM, Kandeel WA, Saber M, Elmosalami DM, Asem N, Fathy AM. Effect of counteracting lifestyle barriers through health education in egyptian type 2 diabetic patients. 
Open access Maced. J. med. sci. 2019 Sep 15;7(17):2886.

47. Shiha G, Metwally AM, Soliman R, Elbasiony M, Mikhail NN, Easterbrook P. An educate, test, and treat programme towards elimination of hepatitis $\mathrm{C}$ infection in Egypt: a community-based demonstration project. Lancet Gastroenterol. Hepatol. 2018 Nov 1;3(11):778 - 89.

48. Salama II, Sami SM, Said ZN, Salama SI, Rabah TM, Abdel-Latif GA, Elmosalami DM, Saleh RM, Mohsin AM, Metwally AM, Hassanin Al. Early and long term anamnestic response to HBV booster dose among fully vaccinated Egyptian children during infancy. Vaccine. 2018 Apr 5;36(15):2005-11.

49. Salama II, Sami SM, Said ZN, El-Sayed MH, El Etreby LA, Rabah TM, Elmosalami DM, Abdel Hamid AT, Salama SI, Abdel Mohsen AM, Emam HM, Elserougy SM, Hassanain Al, Abd Alhalim NF, Shaaban FA, Hemeda SA, Ibrahim NA and Metwally AM. Effectiveness of hepatitis B virus vaccination program in Egypt: Multicenter national project. World J Hepatol. 2015; 7(22): 2418-26.

50. Metwally A, Mohsen A, Saleh R, Foaud W, Ibrahim N, Rabaah T and El-Sayed M. Prioritizing High-Risk Practices and Exploring New Emerging Ones Associated With Hepatitis C Virus Infection in Egypt. Iran J Public Health. 2014; 43 (10):1385-1394.

51. Ahmed AM, Allam MF, Habil ES, Metwally AM, Ibrahiem NA, Radwan M, El Gaafary MM, Gadallah MA. Compliance with haemodialysis practice guidelines in Egypt. EMHJ, 19 (1), 4-9, 2013.

52. Ahmed AM, Allam MF, Habil ES, Metwally AM, Ibrahiem NA, Radwan M, El-Gaafary MM, Afifi A, Gadallah MA. Development of practice guidelines for hemodialysis in Egypt. Indian J. Nephrol. 2010 Oct;20(4):193.

53. Metwally AM, Abdel-Latif GA, Mohsen A, El Etreby L, Elmosalami DM, Saleh RM, El-Sonbaty MM, Amer HA, El Deeb SE, Fathy AM, Hanna C. Strengths of community and health facilities based interventions in improving women and adolescents' care seeking behaviors as approaches for reducing maternal mortality and improving birth outcome among low income communities of Egypt. BMC Health Services Research. 2020 Dec;20(1):1-4.

54. Metwally AM, Saleh RM, El-Etreby LA, Salama SI, Aboulghate A, Amer HA, Fathy AM, Yousry R, El-Deeb SE, Abdel-Latif GA, Elmosalami DM. Enhancing the value of women's reproductive rights through community based interventions in upper Egypt governorates: a randomized interventional study. International journal for equity in health. $2019 \mathrm{Dec} ; 18(1): 1-0$.

55. Metwally AM, Saad A, Ibrahim NA, Emam HM and El-Etreby LA. Monitoring progress of the role of integration of environmental health education with water and sanitation services in changing community behaviours. Int J Environ Health Res. 2007;17(1): 61-74

56. Metwally AM, Ibrahim NA, Saad A and Abu El-Ela MH. Improving rural women role in health and Environmental Issues. Int J Environ Health Res). 2006;16(2):133-44.

57. Buccini GD, Pérez-Escamilla R, Paulino LM, Araujo CL, Venancio SI. Pacifier use and interruption of exclusive breastfeeding: Systematic review and meta-analysis. Matern Child Nutr. 2017 Jul;13(3):e12384.

58. Eidelman Al, Eidelman Al. Routine pacifier use in infants: pros and cons. J. Pediatr. 2019; 95(2):121-3.

59. Silva MD, de Oliveira RD, Alves DD, Melo EC. Predicting risk of early discontinuation of exclusive breastfeeding at a Brazilian referral hospital for high-risk neonates and infants: a decision-tree analysis. Int Breastfeed J. 2021 Dec;16(1):1-3.

60. Ávila-Ortiz MN, Castro-Sánchez AE, Martínez-González, EA, Núñez-Rocha GM, Zambrano-Moreno A. Factors associated with abandoning exclusive breastfeeding in Mexican mothers at two private hospitals. 
Int Breastfeed J. 2020 15, 73.

61. Goon DT, Toriola AL, Shaw BS, Amusa LO, Monyeki MA, Akinyemi O, Alabi OA. Anthropometrically determined nutritional status of urban primary schoolchildren in Makurdi, Nigeria. BMC Public Health. 2011 Dec;11(1):1-8.

62. Flores-Barrantes P, Iguacel I, Iglesia-Altaba I, Moreno LA, Rodríguez G. Rapid Weight Gain, Infant Feeding Practices, and Subsequent Body Mass Index Trajectories: The CALINA Study. Nutrients. 2020; 12(10):3178.

63. Jayasinghe S, Herath MP, Beckett JM, Ahuja KDK, Byrne NM, Hills AP. Anthropometry-based prediction of body fat in infants from birth to 6 months: the Baby-bod study. Eur J Clin Nutr. 2020

64. Blankenship, JL, Cashin, J, Nguyen, TT, Ip, H. Childhood stunting and wasting in Myanmar: Key drivers and implications for policies and programmes. Matern Child Nutr. 2020; 16(S2):e12710.

65. Syeda B, Agho K, Wilson L, Maheshwari GK, Raza MQ. Relationship between breastfeeding duration and undernutrition conditions among children aged 0-3 Years in Pakistan. Int J Pediatr Adolesc Med. 2021 Mar 1;8(1):10 - 7.

66. World Health Organization. Global database on Child Growth and Malnutrition. 2012 Joint child malnutrition estimates - levels and trends. UNICEF-WHO-The World Bank project. Geneva: World Health Organization; 2012 (http://www.who.int/nutgrowthdb/estimates2012/ en/, accessed 8 October 2014)

67. World Health Organization. Global targets 2025. To improve maternal, infant and young child nutrition (/ nutrition_globaltargets2025/en/, accessed60ctober2014).

(www.who.int/nutrition/publications/globaltargets2025_policybrief_wasting/en/accesses 8March 2021

68. Colombo J, Koletzko B, Lampl M (eds): Recent Research in Nutrition and Growth. Nestlé Nutr Inst Workshop Ser. Nestlé Nutrition Institute, Switzerland/S. Karger AG., Basel, (C 2018, vol 89, pp 37-45

69. de Fluiter KS, van Beijsterveldt IALP, Breij LM, Acton D, Hokken-Koelega ACS. Association Between Fat Mass in Early Life and Later Fat Mass Trajectories. JAMA Pediatr. 2020;174(12):1141-1148. doi:10.1001/jamapediatrics.2020.2673

70. El-Masry SA, El Gamal HA, Al-Tohamy M, Nada A, Abdelrahman AH, Metkees MK, Ebrahim A, Saad W. 'Infectobesity' in Egyptian adolescent women and its relations to carotid intima-media thickness. J Arab Soc Med Res 2018;13:79-88

71. Shypailo RJ, Wong WW. Fat and fat-free mass index references in children and young adults: assessments along racial and ethnic lines. Am. J. Clin. Nutr. 2020 Sep 1;112(3):566 - 75.

72. Skau JK, Grenov B, Chamnan C, Chea M, Wieringa FT, Dijkhuizen MA, Ritz C, Wells JC, Berger J, Filteau S, Roos N. Stunting, wasting and breast-feeding as correlates of body composition in Cambodian children at 6 and 15 months of age. Br. J. Nutr. 2019 Mar;121(6):688-98.

73. Council for International Organizations of Medical Science - A nongovernmental organization in official relations with WHO. International Ethical Guidelines for Biomedical Research Involving Human Subjects. Geneva: CIOMS. 2016.

\section{Figures}


Pregnant women and mothers of Infants 0-2 years (target $=646$ )

Women in child bearing period (1454)

\begin{tabular}{|c|}
\hline $\begin{array}{l}\text { First hour lactation } \\
\text { (early breastfeeding } \\
\text { initiation) to reach } \\
50 \%\end{array}$ \\
\hline $\begin{array}{l}\text { - First hour lactation } \\
\text { benefits } \\
\text { - Obstacles for } \\
\text { exclusive breast } \\
\text { feeding and how } \\
\text { to counteracts } \\
\text { them } \\
\text { - Benefits and } \\
\text { reasons for not } \\
\text { using pacifier }\end{array}$ \\
\hline
\end{tabular}

Breast feeding practices

Exclusive
breastfeeding
need to reach $50 \%$

- Benefits

of exclusive breastfeeding during first 6th months

- On Demand breastfeeding

- Start food and water introduction at the age of 6 month.

- Continuation of breastfeeding for 2 years

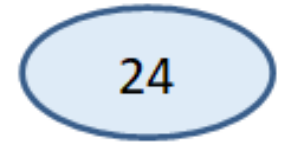

$$
406 / 87.5 \%
$$

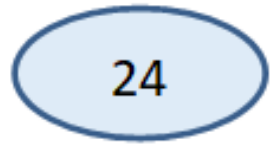

$646 / 100 \%$
Continuation of breastfeeding till age of

24 moths (2years) to reach $50 \%$

- Importance of water consumption of the lactating mother)

- Challenges facing working or busy lactating mother, stories from the community)

- How to start weaning and keep on healthy breastfeeding

\section{Target Group}

\section{Habits}

Key objectives

\section{Counseling Sessions Content}

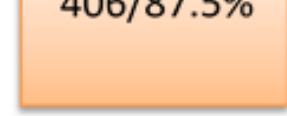

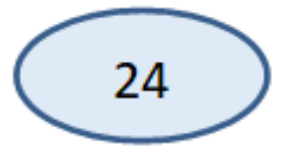

$313 / 67.5 \%$

\section{Sessions no}

Reach and Engagement of the direct beneficiaries

(\% of achievement)
Power point presentation/ Printed posters about positioning/ Listening from the attending mothers about problem they meet in previous breastfeeding experience and offering the best solution for each/ Distribution of photos booklets to mothers to illustrate the right way to breastfed in the first day of birth

Handout with the key messages, book for proper breastfeeding as well as gowns to help mothers to breastfed their infants outside home

\section{Tools}

Give-away

\section{Figure 1}

Flow diagram of the educational interventions implementation process, messages, reach, engagement, tools and demonstrations used to disseminate motives to cause changes 